\title{
Enhanced antioxidant activity and phenolic profile of Ducrosia assadi Alava. by chitosan
}

\author{
${ }^{1 *}$ Mansooreh Khodashenas, ${ }^{1}$ Arsalan Shekarchian, ${ }^{2}$ Najmeh Soleymani \\ ${ }^{1}$ Kerman Agricultural and Natural Resources, Forests and Rangelands Research Department, Research and Education Center, Areeo, Kerman, Iran \\ ${ }^{2}$ Kerman Agricultural and Natural Resources, Department of Agricultural Engineering Research Department, Research and Edcation Center, Areeo, Kerman, \\ Iran
}

Correspondence Author: Mansooreh Khodashenas, Kerman Agricultural and Natural Resources, Forests and Rangelands Research Department, Research and Education Center, Areeo, Kerman, Iran

E-mail: mkhodashenas4@gmail.com

Received date: 12 November 2018, Accepted date: 10 January 2019, Online date: 25 January 2019

Copyright: (C) 2019 Mansooreh Khodashenas et al., This is an open-access article distributed under the terms of the Creative Commons Attribution License, which permits unrestricted use, distribution, and reproduction in any medium, provided the original author and source are credited.

\begin{abstract}
Secondary metabolites are naturally occurring substances in plants. Ducrosia assadii Alava belongs to the family Appiaceae, is a good source of phenolic compounds and natural antioxidants. Chitosan, a glucosamine polysaccharide derived from chitin has known as a biological elicitor. The aim of this study was to evaluate the effect of foliar application of Chitosan $(0,500,750,1000$ and $0.50 \mathrm{mg} / \mathrm{L})$ on the plant metabolite profile, including: total phenolic contents, total flavonoid contents, total anthocyanin contents and free radical scavenging. Free radical scavenging activity was determined according to the elimination of DPPH radicals and expressed by IC50 index. The total phenol and Total flavonoid content was determined by the Folin- Ciocalteu reaction and Aluminum chloride colorimetric method, respectively.

Results showed that chitosan significantly increased all measured traits (except flavonoids). This effect was more obvious at $750 \mathrm{mg} / \mathrm{L}$ concentration. The $\mathrm{IC}_{50}$ of the methanolic extract showed that plants treated with $750 \mathrm{mg} / \mathrm{L}$ had the most free radical scavenging activity. These results emphasized the importance of biotic elicitors for enhancement of the phenolic compounds and the antioxidant activity of $D$. assadii, which might be alternative of genetic modification. Ducrosia assadii is a viable source of natural antioxidants which can be increased by suitable concentration of Chitosan foliar application.
\end{abstract}

Key words: Antioxidant activity, chitosan, DPPH, Ducrosia assadii, phenolic compounds.

\section{INTRODUCTION}

Ducrosia is a member of Apiaceae family. It contains 4 species which occurs in Africa, Asia (especially Iran), Afghanistan, Pakistan, Syria and Iraq. There are 3 species in Iran [1]. Ducrosia species are used as a flavoring additive in foods, beverages, and various desserts and as fragrances in cosmetics [2]. Ducrosia assadii Alava. is an endemic medicinal plant from Iran [3]. The whole herb, especially its aerial parts has been used in Iranian folklore medicine as an analgesic and pain reliever for headache, backache, colic [4]. Furthermore, Biological activities such as antimicrobial, antibacterial and antianxiety effects have been reported for $D$. assadii [5]. The medicinal properties of plants are due to the metabolic compounds that are produced and accumulated during metabolism reactions. The secondary metabolites of the plants are unique resources in the pharmaceutical, food, perfumery and other industries [6]. According to their biosynthetic pathways they are classified into three large molecule families: phenolics, terpenes and steroids, and alkaloids. Phenolic compounds are widespread metabolite family and common to all higher plants.

The main role of the phenolic compounds as the main group of secondary metabolites is the regulation of seed germination and cooperate in regulating the growth of plants, protect plants against pests, diseases, plant pathogens, or to help maintain plant survival against biological or non-biological tensions [7]. It has been well established that reactive oxygen species (ROS) are generated endogenously through a number of biochemical reactions in our body. Uncontrolled generation of ROS can lead to their accumulation causing oxidative stress in the cells. ROS attack lipids, carbohydrates, proteins, DNA, and result in oxidative stress, that leads to various disorders and diseases [8]. 
Recently, much attention has been focused on the potent antioxidative properties of phenolic compounds and conversely their effects in the prevention of various oxidative stress-associated diseases [9]. Today, various methods are used to stimulate the production of secondary metabolites in plants, one of the most important of which is the elicitation. The elicitors are divided into two groups of biological stimuli and non-biological stimuli. Chitosan as a biological stimulus is a glucosamine polysaccharide derived from chitin, which is used to improve secondary metabolites biosynthesis [10]. However, in many cases the production of secondary metabolites can be enhanced by chitosan application [11-12]. Previously, it was reported that the foliar spray of 400 $\mu \mathrm{l} / \mathrm{L}$ chitosan improved biosynthesis of phenols in Thymus daenensis Celak. [13]. Ducrosia species were investigated mainly for their oil analysis and their biological activities. There have been few detailed phytochemical reports on the antioxidant activity of this species [14]. To our best knowledge, antioxidant activity and secondary metabolite enhancement of $D$. assadii has not been studied to date and this is the first report on these subject. In the current work, the effect of foliar application of chitosan on phenolic compounds and antioxidant activity of $D$. assadii was investigated. It is the first report on secondary metabolite of $D$. assadii

\section{MATERIAL AND METHODS}

\section{Plant seeds collection}

The plant seeds were collected in spring 2017 from Bardsir (Kerman Province) located in the South west of Iran.

\section{Plant cultivation and chitosan application}

D. assadii mature seeds were collected from natural habitat located in Hezar Mountain in South East of Iran, Kerman Province. The seeds were surface sterilized by soaking in $70 \%$ ethanol for $1 \mathrm{~min}$ and immediately soaked in $2 \%$ sodium hypochlorite for $10 \mathrm{~min}$. The seeds were rinsed thoroughly with double sterilized water for 30 minutes. Then, the seeds was placed in the refrigerator $\left(+4{ }^{\circ} \mathrm{C}\right)$ for 30 days. Seedlings from seeds were grown in a greenhouse. After 90 days, the plants were randomly treated with different concentrations of the Chitosan as an elicitor. Four different concentrations of the Chitosan were used: $500 \mathrm{mg} / \mathrm{L}, 750 \mathrm{mg} / \mathrm{L}, 1000 \mathrm{mg} / \mathrm{Land} 1250 \mathrm{mg} / \mathrm{L}$. The control plants were treated with distilled water. The treatments were carried out by spraying the aerial parts of the plant at dew point (approximately $100 \mathrm{~mL}$ per plant) 3 times at days 80,83 and 86 . Finally leaves were collected for analysis at day 90.

\section{Extract preparation}

Aliquot $0.5 \mathrm{~g}$ from the aerial parts were extracted with $50 \mathrm{~mL}$ of $80 \%$ aqueous methanol on an ultrasonic bath for $20 \mathrm{~min}$. Then, the extracts were centrifuged for $5 \mathrm{~min}$ at $14000 \mathrm{rpm}$. The supernatant was collected and filtered thoroughly. The extract samples were stored in universal bottles and refrigerated at $4^{\circ} \mathrm{C}$ prior to use.

\section{Determination of total phenolic content}

The total phenolic content (TPC) was determined according to the Folin- Ciocalteu colorimetric method. Briefly, $1 \mathrm{~mL}$ of extract was mixed with $9 \mathrm{~mL}$ of water and $1 \mathrm{~mL}$ of Folin-Ciocalteu reagent. After $5 \mathrm{~min}, 10 \mathrm{~mL}$ of $\mathrm{Na}_{2} \mathrm{CO} 3$ solution $(7.5 \%)$ was added and the samples were brought to the final volume of $10 \mathrm{~mL}$ with water. After 90 min at room temperature, the absorbance was measured at $750 \mathrm{~nm}$ using a UV spectrophotometer. Gallic acid equivalent (GAE) was used as the reference standard and results were expressed as $\mathrm{mg}$ of Gallic acid equivalents per $\mathrm{g}$ of each extract on dry basis (mg GAE.g ${ }^{-1}$ ) (Singleton et al., 1999).[15]

\section{Determination of total flavonoids content}

The total flavonoid content was evaluated using aluminum chloride colorimetric assay. $1 \mathrm{~mL}$ of extracts were taken in a test tube, then $4 \mathrm{ml}$ of distilled water was added, followed by the addition of $0.3 \mathrm{~mL}$ of sodium nitrite $\left(5 \% \mathrm{NaNO}_{2}\right.$, w/v) and allowed to stand for $5 \mathrm{~min}$. Following this, $0.3 \mathrm{~mL}$ of aluminum chloride $\left(10 \% \mathrm{AlCl}_{3}\right)$ was added and the samples were brought to a final volume of $10 \mathrm{~mL}$ with distilled water. The mixture incubated for $15 \mathrm{~min}$ and absorbance was measured at $510 \mathrm{~nm}$. Distilled water was used as blank. Quercetin was used as standard and flavonoid contents were expressed in mg of quercetin equivalents (QE) per gram of extract [16].

\section{Determination of total anthocyanin content}

Aliquot $0.1 \mathrm{~g}$ fresh leaf was homogenized in $10 \mathrm{~mL}$ acidified methanol and the content was kept at $25^{\circ} \mathrm{C}$ for $24 \mathrm{~h}$ in the dark conditions. The homogenate was centrifuged at 4000rpm for $10 \mathrm{~min}$ and the absorbance of the supernatant was determined at 535 $\mathrm{nm}$. The extinction coefficient of 33,000 $\left(\mathrm{mol}^{-1} \mathrm{~cm}^{-1}\right)$ was used to calculate the amount of total anthocyanin content (TAC) and it was expressed as $\mu \mathrm{mol} / \mathrm{g}$ FW [17].

\section{Determination of antioxidant activity}

The DPPH radical scavenging assay was done according to the method of Zhu et al with some [18]. Aliquot $0.5 \mathrm{~g}$ fresh plant material was extracted in $50 \mathrm{~mL}$ of $80 \%$ aqueous methanol with random shaking. After 24 hours the methanolic extract was centrifuged at $30000 \mathrm{~g}$ for $20 \mathrm{~min}$ to abolish plant residues. Then the supernatant was collected and filtered. The filtrate was concentrated through the rotary vacuum evaporator at $35^{\circ} \mathrm{C}$ up to dryness. A solution of $0.004 \%$ (w/v) DPPH in $80 \%$ aqueous methanol was prepared. An aliquot of $2 \mathrm{~mL}$ of DPPH solution was mixed with $2 \mathrm{~mL}$ of the samples dissolved in methanol at different concentrations $(0-100 \mathrm{mg} / \mathrm{mL})$. The reaction mixture was shaken and incubated in the dark at room temperature for 60 min, and the absorbance was read at $517 \mathrm{~nm}$ against the blank. Controls were prepared in a similar way as for the test group 
except for the replacement of the antioxidant solution with the corresponding extraction solvent (methanol). Ascorbic acid was used as standard and calibration curve was drowned. The experiment was carried out in triplicate. The inhibition of the DPPH radical by the sample was calculated according to the following formula:

$\%$ DPPH radical-scavenging $=\mathrm{A}_{0}-\mathrm{A}_{1} / \mathrm{A}_{0} \times 100$.

Where $\mathrm{A}_{0}$ was the Absorbance of control reaction and $\mathrm{A}_{1}$ was the Absorbance in presence of test or standard sample. Results were expressed as the half maximal inhibitory concentration $\left(\mathrm{IC}_{50}\right)$ and compared with Ascorbic acid standard.

\section{RESULTS}

Based on the results of table 1, the chitosan foliar application showed a significant difference in the all measured traits, including TPC, TAC and antioxidant activity, but no significant effect on TFC was observed $(\mathrm{P} \leq 0.05)$.

\section{Effect of chitosan concentration on the total phenolic contents}

In the present study, the treated plants by different concentrations of chitosan (except $1250 \mathrm{mg} / \mathrm{L}$ ) showed higher TPCs content in comparison to non-treated plants (control). The results showed that TPC increased from $28.68 \mathrm{mg}$ GAE/g in control plants to the highest value $(43.51 \mathrm{mg} \mathrm{GAE} / \mathrm{g})$ in plants treated with $750 \mathrm{mg} / \mathrm{L}$ of chitosan. Application of chitosan $1250 \mathrm{mg} / \mathrm{L}$ resulted in a significant decrease of the TPC (Figure. 1).

\section{Effect of chitosan concentration on the total flavonoid contents}

To investigate the effect of chitosan on total flavonoid, various concentrations of chitosan were spray on aerial parts of plants until fully soaked. Regarding to the results of flavonoids contents, no significant difference was observed between treated and non-treated plants (Table. 1). In this respect $1250 \mathrm{mg} / \mathrm{L}$ of Chitosan decreased TFC in comparison to control (Figure. 2).

\section{Effect of chitosan concentration on the total anthocyanin contents}

Data presented in table 1 showed that total anthocyanin content were significantly affected by chitosan. It was found that in plants treated with chitosan, TAC significantly increased from 2.27 to $3.06 \mathrm{mg} / \mathrm{g} \mathrm{FW}$ when $750 \mathrm{mg} / \mathrm{L}$ chitosan was used. Application of $750 \mathrm{mg} / \mathrm{L}$ chitosan increased total anthocyanin content by approximately $35 \%$ (Figure.3)

\section{Effect of chitosan concentration on the antioxidant activity}

The antioxidant activity of the $D$. assadii extracts was determined by measuring their ability to remove free DPPH radicals present in a methanol solution. In this method, the antioxidants react with the DPPH radical and change the color from purple to yellow. Table-5 shows the DPPH radical scavenging activity of different concentrations of extracts which is expressed as $\mathrm{IC}_{50}$ value with respect to ascorbic acid as standard. The lowest $\mathrm{IC}_{50}(33.38 \mu \mathrm{g} / \mathrm{ml})$ was obtained from $750 \mathrm{mg} / \mathrm{L}$ chitosan, which was significantly lower than control group $(62.01 \mu \mathrm{g} / \mathrm{ml})$ (Table. 2 and Figure. 4$)$.

\section{DISCUSSION}

In this study, the chitosan was applied as a biological elicitor, to study its effect on secondary metabolites and antioxidant activity of $D$. assadii. Researchers stated that major compounds of $D$. assadii are comprised of phenolic monoterpenes suchas Chrysantenyl acetat, Citronellol, $\alpha$-pinene, linalool, decanol. Furthermore, this group of phenolic compounds has antioxidant and antimicrobial properties [19-20]. Chitosan has been extensively studied to determine its ability to elicit secondary metabolites In Vivo or In Vitro. In the present research, Comparison of mean TPC showed that spraying of the leaves with chitosan had a significant effect on TPC compared to control plants. TPC increased in all concentrations of chitosan, except $1250 \mathrm{mg} / \mathrm{L}$ which decreased (14\%) in comparison to control. The highest TPC was observed when $750 \mathrm{mg} / \mathrm{L}$ of chitosan was used. In general many reports demonstrated that the production of phenols and flavonoids in plant tissues raises under biotic elicitors [21]. According to Cai et al. (2011) biosynthesis of phenolic compounds in Vitis vinifera by chitosan treatment efficiently was enhanced [22]. Similarly, Kim et al. (2003) reported that chitosan treatment increased the total amount of the phenolic compounds in sweet basil [23].

Furthermore, our observations were concordant with previous reports by Mehregan et al. (2017), who reported spraying of leaves with Citosan $(0.5 \%, 0.1 \%$ and $0.2 \%)$ has significant effect on the content of phenols in Stevia rebaudiana [24] or those by Ramakrishna et al. (2012), who reported chitosan increased production of phenolic compounds in barley [25]. All of these authors considered the increased production of phenolic compounds to be part of the plant defense response system to chitosan. Elicitors are plant signaling molecules that induce gene expression levels of enzymes involved in the synthesis of phenolics compounds via phenylpropanoid pathway of the secondary metabolites [26]. Synthesis of phenolic compounds is recognized initiated very quickly after elicitation.

Important natural compounds found in various parts of plants that have antioxidant properties include poly phenols, flavonoids and anthocyanins, which can act as antioxidants, extinguishing agents, or sweeping active oxygen species in plants. These secondary metabolites are synthesized from the phenylpropanoid pathway. PAL is a key enzyme in this pathway [27]. Although the influence of chitosan application on $D$. assadii secondary metabolites has not been studied yet, possibility chitosan application may activate key enzymes of the phenylpropanoid pathway, in particular PAL. 
As it is shown in the results TFC was generally unaffected by chitosan. The flavonoid contents obtained from treated plants did not show any significant difference to those from the untreated ones, but anthocyanin contents significantly increased. The highest values of TFC observed when $70 \mathrm{mg} / \mathrm{L}$ chitosan was applied. Similarly Portu (2015) has shown that chitosan foliar application did not have any effect on TFC in grape in comparison to control [28], but the other researchers have stated that chitosan applications may lead to enhancement of secondary metabolites especially on flavonoids [29]. Vosoughi et al. (2018) reported that the flavonoids content of the sage extract increased by chitosan application [30]. Similarly Kerch et al. (2011) reported higher values of anthocyanin content for cherries treated with chitosan compare to control plants [31]. These results are concordant with those form Ferri et al. (2009), who reported anthocyanins increasing in response to chitosan treatment, but no difference in the levels of some flavonoids detected between control and chitosan treated samples [32], suggesting that chitosan selectively up-regulates anthocyanin synthesis, without effect on those enzymes related to flavonoid synthesis. It seems that the enzymes responsible for anthocyanin synthesis (ANS) might be activated in preference to those responsible for flavonoid synthesis.

All concentrations of chitosan (500-1250 mg/L) showed stronger DPPH radicals scavenging activity than the untreated plants. In the test of the $\mathrm{DPPH}$ scavenging activity, $\mathrm{IC}_{50}$ is an indicator that $\mathrm{h}$ shows the half of the radicals were scavenged. The Lower $\mathrm{IC}_{50}$ values express the higher antioxidant capacity. By comparing the numerical value of $\mathrm{IC}_{50}$ in the control group and the chitosan treated plants it was stated that all concentration of chitosan reduced this index. Since the inhibition of radical activity percentage and the $\mathrm{IC}_{50}$ have a contrary relationship, it can be concluded that chitosan treatment has increased the percentage of inhibition of free radicals. Therefore, increasing the concentration of phenolic compounds and anthocyanins by chitosan treat ment directly increases the ability of plant extracts to inhibit free radicals. There is a positive correlation between phenols content and antioxidant properties in plants [33]. At higher concentrations of phenolic compounds, due to the increase in the number of hydroxyl groups in aromatic rings, the probability of hydrogen being released to free radicals followed by the inhibitory strength of the extract increases.

\section{CONCLUSION}

D. assadii was analyzed for the first time for its antioxidant activity and secondary metabolites. This study has demonstrated different concentrations of the foliar spray of chitosan increased the total phenol, total anthocyanin and the antioxidant activity of the extracts in this Iranian species. These results emphasized the importance of biotic elicitors for enhancement of the phenolic compounds and the antioxidant activity of $D$. assadii, which might be alternative of genetic modification. Overall, with regard to the results of this study $D$. assadii is a good source of antioxidant compounds and it could be an important source of phenolic compounds with antioxidant capacity.

\section{CONFLICT OF INTEREST}

Authors declare no conflict of interest

\section{REFERENCES}

1. Rechinger K. H., 1987. In Rechinger K. H (ed.) Flora Iranica no.162. - Graz: Akademische Druck und Verlagsanstalt.

2. Shalaby, N M., H.I. Abd-Alla, HF. Aly, MA. Albalawy, KH. Shaker and J. Bouajila, 2014. Preliminary in vitro and in. (2014). Preliminary in vitro and in vivo evaluation of antidiabetic activity of Ducrosia anethifolia Boiss. and its linear furanocoumarins. BioMed research international, 2014, 480545. http://doi.org/10.1155/2014/480545.

3. Mozaffarian, V., 2007. Umbelliferae. In: Assadi, M. et al. (eds.): Flora of Iran, No. 54. - RIFR, Tehran.

4. Shilpa, K., K. Varun and, B S. Lakshmi, 2010. An alternate method of natural drug production: Elciting secondary metabolite production using plant cell culture. Journal of Plant Sciences, 5(3): 222-247.

5. Hajhashemi, V., M. Rabbani, A. Ghanadi and E. Davari, 2010. Evaluation of antianxiety and sedative effects of essential oil of Ducrosia anethifolia in mice. Clinics 65(10): 1037-1042.

6. Mostafavi, A., T. Shamspur, D. Afazali and S. M Mirtadzadini, 2010. Chemical composition of the essential oil of Ducrosia assadii Alava. from Kerman Province in Iran. Journal of Essential Oil Research, 22(4): 300-302.

7. Mazid, M., T. Khan and F. Mohammad, 2011. Role of secondary metabolites in defense mechanisms of plants. Biology and medicine, 3(2): 232-9.

8. Kulbat, K., 2016. The role of phenolic compounds in plant stress responses. Food Sci. Biotechnol, 80: 97-108.

9. Bhattacharya S, 2015. Reactive oxygen species and cellular defense system. InFree radicals in human health and disease. Springer, New Delhi, pp: 17-29.

10. Genwali, GR., PP., Acharya and M. Rajbhandari, 2013. Isolation of gallic acid and estimation of total phenolic content in some medicinal plants and their antioxidant activity. Nepal Journal of Science and Technology, 14(1): 95-102.

11. Zhang, CH., PS. Fevereiro, G. He and Z. Chen, 2007. Enhanced paclitaxel productivity and release capacity of Taxus chinesis cell suspension cultures adapted to chitosan. Plant Science, 172: 158-63.

12. Sathiyabama, M., N. Bernstein and S. Anusuya, 2016. Chitosan elicitation for increased curcumin production and stimulation of defense response in turmeric (Curcuma longa L.). Industrial Crops and Products, 89: 87-94.

13. Jaisi, A. and P. Panichayupakaranant, 2017. Chitosan elicitation and sequential Diaion HP-20 addition a powerful approach for enhanced plumbagin production in Plumbago indica root cultures. Process Biochemistry, 53: 210-215. 
14. Bistgani, Z E., SA. Siadat, A. Bakhshandeh, AG. Pirbalouti, 2017. Morpho-physiological and phytochemical traits of Thymus daenensis Celak. in response to deficit irrigation and chitosan application. Acta Physiol. Plant 39 (10): 231.

15. Assadipour, A., F. Sharififar, M. Robati, V. Samzadeh and K. Esmaeilpour, 2013. Composition and antioxidant effect of the essential oils of the flowers and fruits of Ducrosia assadii Alava. an unique endemic plant from Iran. Journal of Biological Science, 13(4): 288.

16. Singleton, V L., R. Orthofer and R M. Lamuela-Raventós, 1999. Analysis of total phenols and other oxidation substrates and antioxidants by means of folin-ciocalteu reagent. In: Methods in enzymology. Packer, L. Academic Press, pp: 152-178.

17. Zhishen, J., T. Mengcheng, W. Jianming, 1999. The determination of flavonoid contents in mulberry and their scavenging effects on superoxide radicals. Food Chemistry, 64(4): 555-559.

18. Wagner, G J. 1979. Content and vacuole/extravacuole distribution of neutral sugars, free amino acids, and anthocyanin in protoplasts. Plant Physiology, 64(1): 88-93.

19. Zhu, K., H. Zhou and H. Qian, 2006. Antioxidant and free radical-scavenging activities of wheat germ protein hydrolysates (WGPH) prepared with alcalase. Process Biochemistry, 41(6): 1296-1302.

20. Sedaghat, S., 2018. Chemical constituents of essential oil and cytotoxic activity of Ducrosia asadii Alva. from Iran. International Journal of Environmental and Agriculture Research, 4(5): 44-46.

21. Habibi, H., N. Ghahtan and L. Karami, 2018. Chemical Compound Analysis and Antibacterial Effect of Five Medicinal Plants Essential Oils on Infectious Bacteria. Trends in Pharmaceutical Sciences, 4(1): 51-58.

22. Weidner, S., M. Karolak, M. Karamac, A. Kosinska and R. Amarowicz, 2009. Phenolic compounds and properties of antioxidants in grapevine roots followed by recovery. Acta Societatis Botanicorum, 78: 279-286.

23. Cai, Z., H. Riedel, N. M. M. T. Saw, O. Kütük, , I. Mewis, and I. Smetanska, 2011. Effects of pulsed electric field on secondary metabolism of Vitis vinifera L. cv. Gamay Fréaux suspension culture and exudates. Applied biochemistry and biotechnology. 164(4): 443-453.

24. Kim, H J., F. Chen, X. Wang and NC 2005. Effect of chitosan on the biological properties of sweet basil Ocimum basilicum L. Journal of Agricultural and Food Chemistry, 53(9): 3696-3701.

25. Mehregan, M., A. Mehrafarin, M.R. Labbafi and H Naghdi Badi, 2017. Effect of different concentrations of chitosan biostimulant on biochemical and morphophysiological traits of stevia plant (Stevia rebaudiana Bertoni). Journal of Medicinal Plants, 16:169-181.

26. Ramakrishna, R., D. Sarkar, A. Manduri, S.G. Iyer, and K. Shetty, 2017. Improving phenolic bioactive-linked antihyperglycemic functions of dark germinated barley sprouts (Hordeum vulgare L.) using seed elicitation strategy. Journal of Food Science and Technology, 54(11): 3666-3678.

27. Singh, S., 2016. Enhancing phytochemical levels, enzymatic and antioxidant activity of spinach leaves by chitosan treatment and an insight into the metabolic pathway using DART-MS technique. Food Chemistry, 199: 176-184.

28. Chen Z, Zheng Z, Huang J, Lai Z, Fan B (2009). Biosynthesis of salicylic acid in plants. Plant Signal Behavior, 4(6): 493496.

29. Portu, J., R., López, E. Baroja, P. Santamaría, and T Garde-Cerdán, 2016. Improvement of grape and wine phenolic content by foliar application to grapevine of three different elicitors: Methyl jasmonate, chitosan, and yeast extract. Food Chemistry, 201: 213-221.

30. Orlita, A., M. Sidwa-Gorycka, M. Paszkiewicz, E. Malinski, J. Kumirska, E.M. Siedlecka, E. Łojkowska, and P Stepnowski, 2008. Application of chitin and chitosan as elicitors of coumarins and furoquinolone alkaloids in Ruta graveolens L. (common rue). Biotechnology and Applied Biochemistry. 51(2): 91-96.

31. Vosoughi, N., M. Gomarian, AG. Pirbalouti, S. Khaghani and F. Malekpoor, 2018. Essential oil composition and total phenolic, flavonoid contents, and antioxidant activity of sage (Salvia officinalis L.) extract under chitosan application and irrigation frequencies. Industrial Crops and Products, 117: 366-374.

32. Kerch, G., M. Sabovics, Z. Kruma, S. Kampuse and E. Straumite, 2011. Effect of chitosan and chitooligosaccharide on vitamin $\mathrm{C}$ and polyphenols contents in cherries and strawberries during refrigerated storage. European Food Research and Technology, 233(2): 351-358.

33. Ferri, M., A., Tassoni, M. Franceschetti, L. Righetti, MJ. Naldrett and N. Bagni, 2009. Chitosan treatment induces changes of protein expression profile and stilbene distribution in Vitis vinifera cell suspensions. Proteomics 9(3): 610-24.

34. Stanković, M. S., M. Petrović, D. Godjevac, Z. D. Stevanović, 2015. J Arid Environ, 120: 26-32. 